\title{
Prediction of curve progression for AIS patients treated with a TLSO Brace
}

\author{
E Lou*1,2, D Hill11,2, E Parent ${ }^{1,2}$, J Raso ${ }^{1,2}$, M Moreau $^{1,2}$, J MAhood ${ }^{1,2}$ and \\ D Hedden ${ }^{1,2}$
}

\author{
Address: ${ }^{1}$ Department of Rehabilitation Technology, Glenrose Rehabilitation Hospital - Edmonton, AB Canada and ${ }^{2}$ Department of Surgery, \\ University of Alberta, Edmonton, AB, Canada \\ Email: E Lou* - edmond.lou@capitalhealth.ca \\ * Corresponding author
}

from 6th International Conference on Conservative Management of Spinal Deformities

Lyon, France. 2I-23 May 2009

Published: 14 December 2009

Scoliosis 2009, 4(Suppl 2):O38 doi:10.1 I86/1748-7|61-4-S2-O38

This abstract is available from: http://www.scoliosisjournal.com/content/4/S2/O38

(c) 2009 Lou et al; licensee BioMed Central Ltd.

\section{Objective}

The objective of this study was to develop a curve progression model for patients with AIS receiving brace treatment by considering compliance measures and in-brace correction factors.

\section{Background}

Bracing is the most commonly used non-surgical treatment for adolescent idiopathic scoliosis (AIS). Prediction of brace treatment outcomes has not been well documented.

\section{Method}

Twenty subjects (17 females, 3 males), aged $13.4 \pm 1.8$ years, were prescribed a full-time TLSO ( $22 \mathrm{hr} /$ day) and were monitored and followed for 3 years. All subjects met the SRS Brace Study inclusion criteria. The brace usage in terms of quantity (percent of wear time relative to the prescribed wear) and quality (percent of wear tightness relative to the prescribed tightness level) was logged with a compliance monitoring system. The Peterson's risk of progression at the time when the brace was prescribed was calculated based on 4 variables: Risser sign, apex of the curve, age, and imbalance. In-brace curve correction (flexibility) was calculated using the following: (Initial Cobb in-brace Cobb)/Initial Cobb. A predictive model for curve progression using regression was developed based on the Peterson's risk of progression, quantity, quality, and the percentage of in-brace correction. Data from six new subjects who used a monitoring system and were followed for 2 years after bracing was used to assess the validity of the model.

\section{Results}

The Cobb angles of the subjects pre-brace $(n=9)$, inbrace $(n=8)$ and 3 years after weaning $(n=23)$ were 32 , 11 , and 35 degrees, respectively. The individual parameters, including Peterson's risk of progression, flexibility, quality, quantity, and quality* quantity, contributed to the curve progression model were $8 \%, 19 \%, 15 \%, 8 \%$ and $14 \%$, respectively. Combining all variables, $56 \%$ of the variance in curve progression can be predicted. The curve progression model was: curve Progression (in degrees) = $33+0.11^{*}$ Peterson Risk (\%) - 0.07 in-brace correction (\%) - $0.45^{*}$ Quality (\%) - $0.48^{*}$ Quantity (\%) + $0.62 *$ Quantity*Quality. The results from the 6 new subjects are in table I. The largest prediction error of the prediction model was 3 degrees.

\section{Conclusion}

It is possible to predict the curve progression for AIS patients who have brace treatment. 